\title{
Medicinal plants used by the Yi ethnic group: a case study in central Yunnan
}

\author{
Chunlin Long*1,2, Sumei Li13,6, Bo Long1,3, Yana Shi1,4 and Benxi Liu ${ }^{5}$
}

Address: ${ }^{1}$ Kunming Institute of Botany, Chinese Academy of Sciences, Kunming 650204, PR China, ${ }^{2}$ College of Life and Environmental Sciences, Minzu University of China, Beijing 100081, PR China, ${ }^{3}$ Graduate School, Chinese Academy of Sciences, Beijing 100039, PR China, ${ }^{4}$ College of Horticulture, Yunnan Agricultural University, Kunming 650201, PR China, ${ }^{5}$ Chuxiong Research Institute of Yi Medicine and Pharmacology, Yunnan 671000, PR China and ${ }^{6}$ South China Sea Institute of Oceanology, Chinese Academy of Sciences, Guangzhou 510301, PR China

Email: Chunlin Long* - chunlinlong@hotmail.com; Sumei Li - lism@scsio.ac.cn; Bo Long - longbo@mail.kib.ac.cn;

Yana Shi - bestshiyana@163.com; Benxi Liu - newyuxi@yahoo.com.cn

* Corresponding author

Published: 23 April 2009

Journal of Ethnobiology and Ethnomedicine 2009, 5:13 doi:10.1 186/1746-4269-5-13
Received: 25 January 2009

Accepted: 23 April 2009

This article is available from: http://www.ethnobiomed.com/content/5/1/13

(c) 2009 Long et al; licensee BioMed Central Ltd.

This is an Open Access article distributed under the terms of the Creative Commons Attribution License (http://creativecommons.org/licenses/by/2.0), which permits unrestricted use, distribution, and reproduction in any medium, provided the original work is properly cited.

\begin{abstract}
Background: This paper is based on ethnomedicinal investigation conducted from 1999-2002 in Chuxiong, central Yunnan Province, Southwest China. The Yi medicine has made a great contribution to the ethnomedicinal field in China. Neither case studies nor integrated inventories have previously been conducted to investigate the traditional $Y i$ plants. This paper aims to argue the status and features of medicinal plants used in traditional $Y i$ societies through a case study.

Methods: The approaches of ethnobotany, anthropology, and participatory rural appraisal were used in the field surveys. Twenty-two informants in four counties were interviewed during eight field trips. Medicinal plant specimens were identified according to taxonomic methods.

Results: One hundred sixteen medicinal plant species were found to be useful by the local people in the treatment of various diseases or disorders, especially those relating to trauma, gastrointestinal disorders and the common cold. Among these 116 species, 25 species (21.55\%) were found to have new curative effects and 40 species (34.48\%) were recorded for their new preparation methods; 55 different species were used in treating wounds and fractures, and 47 were used to treat gastrointestinal disorders. Traditional Yi herbal medicines are characterized by their numerous quantities of herbaceous plants and their common preparation with alcohol.

Conclusion: Totally 116 species in 58 families of medicinal plants traditionally used by the $\mathrm{Yi}$ people were inventoried and documented. The characteristics of medicinal plants were analyzed. Some new findings (such as new curative effects and new preparation methods) were recorded These newly gathered ethnobotanical and medicinal data are precious sources for the future development of new drugs, and for further phytochemical, pharmacological and clinical studies.
\end{abstract}

\section{Background} Study Area

Chuxiong Prefecture, located in the north of middle Yunnan Plateau $\left(24^{\circ} 13^{\prime}-26^{\circ} 30^{\prime} \mathrm{N}, 100^{\circ} 43^{\prime}-102^{\circ} 43^{\prime} \mathrm{E}\right)$, has numerous high mountains, deep canyons, and large and small rivers. Mountainous land in Chuxiong occupies over $90 \%$ of its total territory. Chuxiong's climate is considered a sub-tropical and moist plateau monsoon cli- 
mate, primarily affected by two air currents: a warm, dry current from northern Africa, the Middle-East and the subcontinent of India during winter and a cool, moist current from the Indian Ocean and Bay of Bengal during summer. The climate of Chuxiong is characterized by long spring and autumn and short summer and winter. Although the daily temperature can vary greatly, the climate is generally temperate and without extremes [1]. The Ailao Mountains contain large forests and are abundant with medicinal plants. The Yi have utilized these plants in the prevention and cure of disease for centuries. Some 871 species of Yi plant medicines have currently been recorded [2].

\section{Population}

With the exception of the Han Chinese, there are 55 minority nationalities in China. Each of them has their own unique history and medicinal system. With a population of 6.57 million, the Yi are the sixth largest minority in China, distributed in Yunnan, Sichuan, Guizhou and Guangxi provinces. In the southwest of China, Yunnan holds the largest population of the Yi nationality [1], which reaches 4.06 million.

\section{Aim of study}

Research into the literature reveals that most of the ancient books on Yi medicine were handed down by dictation and are hand-written. Therefore, there must be additional traditional knowledge on Yi medicine that was scattered among folk areas and unrecorded, including some proven remedies with special curative effects preserved by folk doctors [3]. We thus decided to collect the folk knowledge of Yi medicine in Chuxiong Prefecture to compliment the previously documented works on traditional Yi medicine.

\section{Previous knowledge on local folk medicine}

The Yi people mainly inhabit mountainous areas or river valleys. The particular geology and climate is ideal for a unique Yi medicine effective in treating pyretic toxicity, rheumatics, etc. Yi medicine, practiced for 3000 years, is derived from Dali medicine of the Nanshao Kingdom. By assimilating the best of local, Indian, and Persian medicine [4], the Yi people built their own medicinal theoretical system. The Yi acquired extensive clinical experience and recorded the pertinent knowledge in books, such as Xian Yao Jing, Shuangbai Medicinal Book of Yi Nationality, Book for Curing Diseases, and others. The earliest book of Yi medicine is The Shuangbai Medicinal Book of Yi Nationality, written even earlier than Shi-Zhen Li's Ben Cao Gang Mu in 1758. As we know, traditional medicine (TM) is widely used and is of increasing importance in a rapidly growing global health and economic system. In Africa, up to $80 \%$ of the population uses TM to help to meet their health care needs. In Asia and South America, populations continue to use TM as a result of historical circumstances and cultural beliefs. In China, TM accounts for around $40 \%$ of all health care delivered [5]. Given these statistics, we should cherish, protect and develop upon the legacy that is traditional Yi medicine.

The majority of products which were exploited in recent years based on Yi medicines have provided positive social and financial benefits. The famous Yi doctor, Huan-Zhang $\mathrm{Qu}$, researched and developed the outstanding Yunnan Bai Medicine [6]. Similar drugs such as the Capsule of Paiduyangyan, the Kunming Shanhaitang, the Injection of Yunnan Dengzhanhua, Injection of Sanqi saponin, Capsule of Yixinkang and others have all been developed following deep research into the culture of traditional Yi medicine. The selling price of these drugs derived from traditional $\mathrm{Yi}$ medicines could reach 10 billion Chinese Yuan (or 1.26 billions in US dollars) per year [6].

Indigenous knowledge, and folk knowledge in particular, continues to be impacted by mainstream culture and decreasing biodiversity; traditional practices using specific medicinal plants decreases more quickly than that of the general biodiversity. It is thus urgent and necessary to prevent the further loss of the specialized knowledge of minority peoples. This is best accomplished by gathering and documenting their unique practices and their relationships to medicinal plants [6].

\section{Methodology}

Eight field surveys in four counties were carried out during different seasons over a period of four years (1999-2002). These four locations in Chuxiong Prefecture consisted of: Wuding, Shuangbai and Nanhua counties, and Chuxiong City. The methodological approaches were used in ethnobotany, anthropology, and participatory rural appraisal (PRA) [7-10] were adopted for the field investigations.

During each visit, detailed field records were taken on the functions of plants and the plant parts that were used. Information was obtained through interviews with 32 informants including elderly villagers, local healers, and herbalists. The authors collected voucher specimens of 116 plants in the field with assistance from local herbalists. The specimens were later verified using The Flora of China and Illustrated Handbook for Higher Plants of China $[11,12]$, and by the authors, plant taxonomists, and experts from the authors' institution. The voucher specimens were deposited in the Voucher Herbarium of the Laboratory of Ethnobotany, Kunming Institute of Botany, Chinese Academy of Sciences. The local names of the herbs, their life forms, preparation methods, and their 
useful parts for treating various diseases were carefully recorded in the field [13]. The efficacy of these plants was also analyzed and compared with the pertinent literature.

\section{Results}

\section{Statistics of plants used}

One hundred and sixteen plant species used for medicinal purposes by people living in Chuxiong Prefecture of Yunnan Province were collected and identified (Additional file 1). These species are represented by 58 different families, of which Compositae (15 species), Rosaceae (6 species), and Liliaceae, Papilionaceae and Orchidaceae (each with 5 species) hold the highest number of species used medicinally. One hundred and four genera are represented: Ainsliaea, Artemisia, Clematis, Clerodendrum, Conyza, Corydalis, Cynanchum, Indigofera, Pholidota, Polygala, Polygonum and Rubus all occurring twice.

25 previously unidentified species $(21.55 \%)$ were found to have new curative effects and 40 species (34.48\%) had preparation methods that have never been recorded in the contemporary medical texts of the Yi nationality in Chuxiong Prefecture (Additional file 1) [14-17].

\section{Medicinal uses}

The three most common conditions treated with Yi plants were: trauma, such as wounds and fractures, for which 55 different species were used, eg. Crepis napifera and Gaultheria yunnanensis; gastrointestinal disorders, such as stomachache, diarrhea, and constipation; and the common cold, such as fever, cough, sore throat and influenza (for example, Murraya paniculata and Polygonum cymosum) (Table 1). Only nine species were reported as being useful against a single disease, eg. Ranunculus ternatus and Euonymus japonicus.

\section{Plant habit and part used}

Seventy two plants, over half of the species used medicinally, were herbaceous in nature (eg. Ainsliaea yunnanensis and Cucubalus baccifer), while 33 were woody, i.e. tree, shrub, or woody liana (eg. Aquilaria sinensis and Toona sinensis), and 11 were sub-shrubs. The entire plant was used most often, accounting for 65 species out of 116 (56.03\%), followed by the roots, of 42 species out of 116 (36.21\%); other plant parts were used less frequently, about $7.76 \%$.

\section{Preparing methods of medicinal plants}

As shown in Additional file 1, the preparing methods of medicinal plants were different and special. Eighty-eight species could be taken by decoction, which was the most common preparing method. Seventeen species should be used after they were soaking in alcohol. Four species could be used after making juice for drinking or external uses. Fourteen species could be used by making powder. Some
Table I: List of the frequency of ailments treated with medicinal plants

\begin{tabular}{lll}
\hline Disease & Species used & $\%$ of total \\
\hline Trauma & 55 & $47.41 \%$ \\
Gastrointestinal disorders & 47 & $40.52 \%$ \\
Common cold & 24 & $20.69 \%$ \\
Skin problems & 20 & $17.24 \%$ \\
Liver problems & 19 & $16.38 \%$ \\
Gynaecopathia & 18 & $15.52 \%$ \\
Inflammation & 13 & $11.21 \%$ \\
Trachea/bronchi disorder & 12 & $10.34 \%$ \\
Edema & 11 & $9.48 \%$ \\
Lung problems & 11 & $9.48 \%$ \\
Antitoxics & 10 & $8.62 \%$ \\
Heart problems & 10 & $8.62 \%$ \\
Body pains & 9 & $7.76 \%$ \\
Female issues & 5 & $4.31 \%$ \\
Blood problems & 4 & $3.45 \%$ \\
Eye problems & 4 & $3.45 \%$ \\
Kidney problems & 4 & $3.45 \%$ \\
Neural diseases & 3 & $2.59 \%$ \\
Cypridopathy & 2 & $1.72 \%$ \\
Ear problems & 2 & $1.72 \%$ \\
Mouth cavity problems & 2 & $1.72 \%$ \\
Infectious disease & 1 & $0.86 \%$ \\
Parasitic diseases & 1 & $0.86 \%$ \\
Rhachitis & 1 & $0.86 \%$ \\
Tooth problems & 1 & $0.86 \%$ \\
\hline
\end{tabular}

species should be used together with other species, or with sugar, honey, meat, eggs, chicken, or other materials.

\section{Conclusion}

In the present study, 116 species belonging to 58 families have been identified as medicinal plants used by Yi healers in Chuxiong Prefecture, Yunnan Province. These plants have unique properties and are used in the treatment of trauma, gastrointestinal disorders and the common cold. From the statistic data, we found most of the plants are used to treat trauma. This is because the primitive ancestors of the Yi people usually lived in tree crotches and made their living by hunting and gathering [6], which made them vulnerable to injury. The medicinal plants used to treat gastrointestinal disorders accounts for the second largest percentage. This result can be explained by the epidemiological research on Helicobacter pylori (Hp) among Yi communities. The Yi people were easily infected by $\mathrm{Hp}$, which has a strong correlation with their fondness for drinking distilled spirits, smoking, and eating pickled, fermented, and fried food [18].

There are several characteristics of traditional Yi medicine. Most plants used in Yi medicine are herbaceous as shown in Additional file 1. Among 116 medicinal plant species traditionally used by the Yi healers in the case sites, 72 species are either perennial or annual herbs, or herba- 
ceous lianas. This is partially due to the Yi's polytheistic beliefs. The Yi believe that both mountains and big trees are sacred and should not be harmed [19]. This perception of nature plays a positive role on the protection of the vegetation around their dwelling places. The minorities who live in mountainous areas would never intentionally damage their natural environment and aim to exist in harmony with it. That is why many scholars advocate that people living in modern society learn from the minority people, to respect the environment rather than depredating it [20-25].

Fresh herbs are used almost exclusively by Yi healers. Dry herbs are used, but much less frequently. The Yi healers usually used a single herb instead of multi-species compounds. For example, when the Yi healer treated wounds with Gaultheria yunnanensis, he would not mix it with any of the other (over 50) species he knew that could also treat wounds. Some healers were less concerned about measuring doses when administering medicinal herbs. Medicinal plant preparation methods vary: For external application, plants are generally pounded, kneaded or chewed; for oral doses, plants are often chewed, decocted or cooked with meat.

Traditional Yi medicine is especially characterized by its use of alcohol. The Yi people adore alcohol, and it has come to symbolically represent this cultural minority due to its significance in their lives. Home-made alcohol is the most important beverage for the Yi: it is used daily, for ceremonies and holidays, served to respected guests and friends, and is the most common method of administering plant medicines. The practice of combining plants and alcohol has a long history in Yi medicine. Yi healers use different procedures to administer their raw material/ alcohol combinations. They most commonly use: 1) medicinal alcohol: medicinal plants and/or animals are soaked in alcohol for about a month and the resulting liquid then is drunk by the patient or applied externally to the affected parts; 2) alcohol decoction: herbs are put into alcohol, decocted and drunk; 3) alcohol as solvent instead of water: fresh plant liquid or dried plant powder is placed in alcohol and either drunk or applied externally; and 4) burning alcohol in medicine: medicinal plants are mixed with alcohol, heated, and then either taken by mouth or applied externally. It is believed that alcohol extracts more active components from the medicinal plants than water does, thus being more effective in curing diseases. For example, Ainsliaea latifolia var. obovata, when soaked in alcohol, is far more effective in treating children's fever than the fresh plant alone. This traditional knowledge was previously unreported.

Since natural medicines can cure diseases ranging from bacterial infections to cancers, pharmaceutical companies and the public recognize the importance of its development. Most of the pharmaceutical companies believe that the biggest benefit hiding behind the traditional plant knowledge and practices of minority people is the value of new drug development [2].

Biodiversity is a rare gift provided by nature to those researching chemo-diversity and the discovery of new drugs. This chemo-diversity not only provides the necessary secondary metabolites of plant evolution, but also provides abundant lead compounds, the basis of new drug development [2]. Due to the side-effects associated with chemosynthetic medicine and environmental pollution, medical scientists from both here and abroad have begun to look into the realm of traditional medicine, which has used natural medicine as its main remedial measure [26]. During our research, we found twenty five species with previously undocumented curative effects and forty species whose preparation methods and compatibilities had not been documented. These new records can be an important source for further phytochemical, pharmacological and clinical studies.

We suggest that the traditional knowledge of the Yi could provide useful information in finding new drugs that contribute to human welfare.

\section{Competing interests}

The authors declare that they have no competing interests.

\section{Authors' contributions}

Author C Long conducted field surveys and interviews with the healers, identified the herbarium specimens, drafted and finalized the manuscript with S Li and Y Shi. Author B Long provided assistance when preparing the manuscript. Author B Liu helped to analyze the data.

\section{Additional material}

\section{Additional file 1}

Inventory of Traditional Herbal Plants Used by the Yi People. One hundred and sixteen plant species used for medicinal purposes by people living in Chuxiong Prefecture of Yunnan Province.

Click here for file

[http://www.biomedcentral.com/content/supplementary/17464269-5-13-S1.pdf]

\section{Acknowledgements}

This study was supported by the Ministry of Education of China through its III and 985 projects (B08044 \& MUC 985-3-3), the Ministry of Science \& Technology of China (2008FYII 0400 \& 2005DKA2 1006), the MacArthur Foundation, and the International Centre for Integrated Mountain Development. We are grateful to the local healers and farmers in Chuxiong, who provided their precious time and useful information when we conducted 
our field trips. Krisa Fredrickson, an ethnobotanist at the California Academy of Sciences, USA, has critically read the manuscript and edited the English. Special thanks go to our colleagues, Fang-yu Zhang, Jie-ru Wang, Yi-tao Liu, Li-min Chen, Ai-zhong Liu, San-yang Chen and Sheng-ji Pei.

\section{References}

I. Compilation Council of $\mathrm{Yi}$ Nationality Autonomous Prefecture Chorography of Chuxiong: Yi Nationality Autonomous Prefecture Chorography of Chuxiong. Beijing: People's Press; 1993.

2. Qi L, Luo SD: Collection of Chinese Minorities Medicine. Hohhot: Science and Technology Press of Inner Mongolia; 2000.

3. Yang BL, Yang QY: Topic on the collection and development of Yi people's prescription. Yunnan Journal of Traditional Chinese Medicine and Herbs 2002, 23(I):4I.

4. Zhang XS: Existent crisis faced by Yi medicine of Yunnan. Enterprise Economy 2005, 6:27.

5. World Health Organization: WHO Traditional Medicine Strategy 2002-2005. [http://www.who.int/medicines/publications/tradi tionalpolicy/index.html]. World Health Organization, Geneva

6. Zhang Y, Meng XL, Zhang J, Wang MW: Ethnopharmacology and development of new medicine. World Science and Technology/ Modernization of Traditional Chinese Medicine and Materia Medical 2005, 7(5):54.

7. Lipp FJ: Methods for ethnopharmacology field work. J Ethnopharmacol 1989, 25:139.

8. Etkin N: Anthropological methods in ethnopharmacology. J Ethnopharmacol 1993, 38:93.

9. Hedberg I: Botanical methods in ethnopharmacology and the need for conservation of medicinal plants. J Ethnopharmacol 1993, 38:121.

10. Pei SJ, Long CL: The Applied Ethnobotany. Yunnan: Yunnan Minority Press; 1998.

II. Institute of Botany, Chinese Academy of Sciences: Iconographia Cormophytorum Sinicorum. Beijing: Science Press; 1987.

12. Editorial Committee of Flora Reipublicae Popularis Sinicae: Flora Reipublicae Popularis Sinicae. Beijing: Science Press; 2004.

13. Alba RM, Brito S: How to study the pharmacology of medicine plants in underdeveloped countries. J Ethnopharmacol 1996, 54:131.

14. Institute for Drug Control of Yunnan Chuxiong Yi Autonomous Prefectural Health Board: Records of Yi Medicine. Sichuan: Nationalities Publishing House of Sichuan; 1983.

15. Wang ZK, Zhou MK: Herbalism of the Ailao Mountains. Shanxi: Science and Technology Press of Shanxi; 1991.

16. Liu XY, Qi T: Yi Medicine of China. Beijing: Science Press; 1996.

17. Wang M, Zhu JY: Yi Nationality Herbalism of Chuxiong. Yunnan: People's Press of Yunnan; 1998.

18. Liu YY, Zhou ZF, Nan Q, Ma LQ, Wang J, Jin L, Hu YY, Zhang JY, Li $X Y$, Duan LP, Wei YM, Qi GR, Gui YJ: Epidemiological investigation on Helicobacter pylori $(\mathrm{Hp})$ among two $\mathrm{Yi}$ communities of Yuxi Prefecture in Yunnan. Yunnan Medicine 2003, 24(6):442.

19. Ang ZM: Bimo-transfer and bear the reverence of human to nature. Man and Biosphere 2005, I:49.

20. Yang CY, Pei CX, Long CL: Relationship between traditional culture of Dong nationality and biodiversity. Biodiversity Science I 995, 3(I):44.

21. Yin ST: People and Forests - Yunnan Swidden Agriculture in Human - An Ecological Perspective. Yunnan: Yunnan Education Publishing House; 2000.

22. Long CL, Abe T, Wang H, Li ML, Yan HM, Zhou YL: Biodiversity management and utilization in the context of traditional culture of Jinuo society in S Yunnan, China. Acta Botanica Yunnanica 1999, 2 I (2):239.

23. Long CL, Li H, Dao ZL, Zhou YL: Ethnobotanical studies in Gaoligong Mountains: I. The Lemo people. Acta Botanica Yunnanica | 999, XI(Suppl): | 3 |.

24. Long CL, Zhang FY, Pei SJ, Chen SY: Impacts of traditional culture of Yi nationality upon biodiversity in Zixishan Mountain area, Yunnan. Biodiversity Science 1999, 7(3):245.

25. Mu WC: Bulang nationality's concept to forest and their forestry cultivation mode. Ecological Economy 2003, I I: 18.

26. Gu J, Liu Z: Status of the development of plant medicine of $\mathbf{Y i}$ nationality. Chinese Journal of Ethnomedicine and Ethnopharmacy 2003, 64:249.
Publish with Biomed Central and every scientist can read your work free of charge

"BioMed Central will be the most significant development for disseminating the results of biomedical research in our lifetime. "

Sir Paul Nurse, Cancer Research UK

Your research papers will be:

- available free of charge to the entire biomedical community

- peer reviewed and published immediately upon acceptance

- cited in PubMed and archived on PubMed Central

- yours - you keep the copyright
BiolMedcentral 